\title{
Automatic Stamping Charger-Stamping of Blended Coal-Theorical Study and Practice Analysis at TKCSA
}

\author{
Yan Samuel Ferreira Junqueira ${ }^{1}$, Leonardo de Souza Pinto ${ }^{2}$, Robson Coelho ${ }^{1}$ and Jose Maria Clemente ${ }^{3}$ \\ 1. Technical Unit Iron Making, ThyssenKrupp CSA, Rio de Janeiro 23560-352, Brazil \\ 2. Coke Plant Maintenance Department, ThyssenKrupp CSA, Rio de Janeiro 23560-352, Brazil \\ 3. Independent Consult, Vitoria, Brazil
}

\begin{abstract}
The coke plant of a steel plant corresponds to the area that transforms a blend of coal into coke for using in blast furnace and steam to power plant. The coking plant of ThyssenKrupp CSA uses the heat recovery technology with stamping charger for stamping and preparation a blend of coals for charging and coking. Stamping technology adds several benefits to the process, such as increased density, homogeneity and alignment of the coal cake charged into the oven, as well as provides better control of the coking process, improves parameters of coke quality and allows coal blending with lower coking power, thereby reducing the production cost of coke and power generation. Through the automation of stamping charger, it is possible to evaluate and calculate the stamped coal density charged and the productivity gains this system provides.
\end{abstract}

Key words: Stamping charger, density, automatic, coke plant.

\section{Introduction}

The application of the stamping charger technique in the coking process seeks to confer similar properties to the blended coal with certain desired particle size distribution and moisture with the aim of minimizing the empty space between the grains, allowing sufficient integrity to the blended coal for handling and charging.

The immediate gain of this stamping/ homogenization is the increased density of coal cake charged into the oven $\left(\mathrm{t} / \mathrm{m}^{3}\right)$ and consequently, the coke production increases. There are other gains such as, alignment of the coal cake, better control of combustion in the oven and increase of some quality parameters, such as CSR (coke strength after reaction). This quality increase can be reversed in cost reduction gains, since it allows using coal with lower quality and lower cost, without decreasing the quality and productivity of the coke battery. This study presents how to increase productivity using the stamping

Corresponding author: Yan Samuel Ferreira Junqueira, automation engineer, research fields: heat recovery coke oven, stamping charger, and thermal control. charger at TKCSA (ThyssenKrupp Companhia Siderúrgica do Atlântico) through its automation, aiming at increasing charge density, better control of the coking process, increasing the quality and reducing production cost with the ability to use lower quality coals.

\section{Stamping Charger Process Description}

The stamping process using stamping charger has an objective of ensure maximum density and amount of coal to be charged. The system uses a stamping pressure of $130 \mathrm{bar}$, which considering the moisture and particle size in the optimum range could reach a compression rate of about $35 \%$. The controller moves the hopper at predefined positions and the stamps compress the blended coal in order to obtain a density of $1.12 \mathrm{t} / \mathrm{m}^{3}$. The process will be completed when three layers are distributed and stamped, as shown in Fig. 1.

\subsection{Influence of the Moisture in the Stamping Process}

Ralph Proctor (1933) developed a dynamic test to determine the point of maximum compression which gets the optimum moisture for compression. Fig. 2 

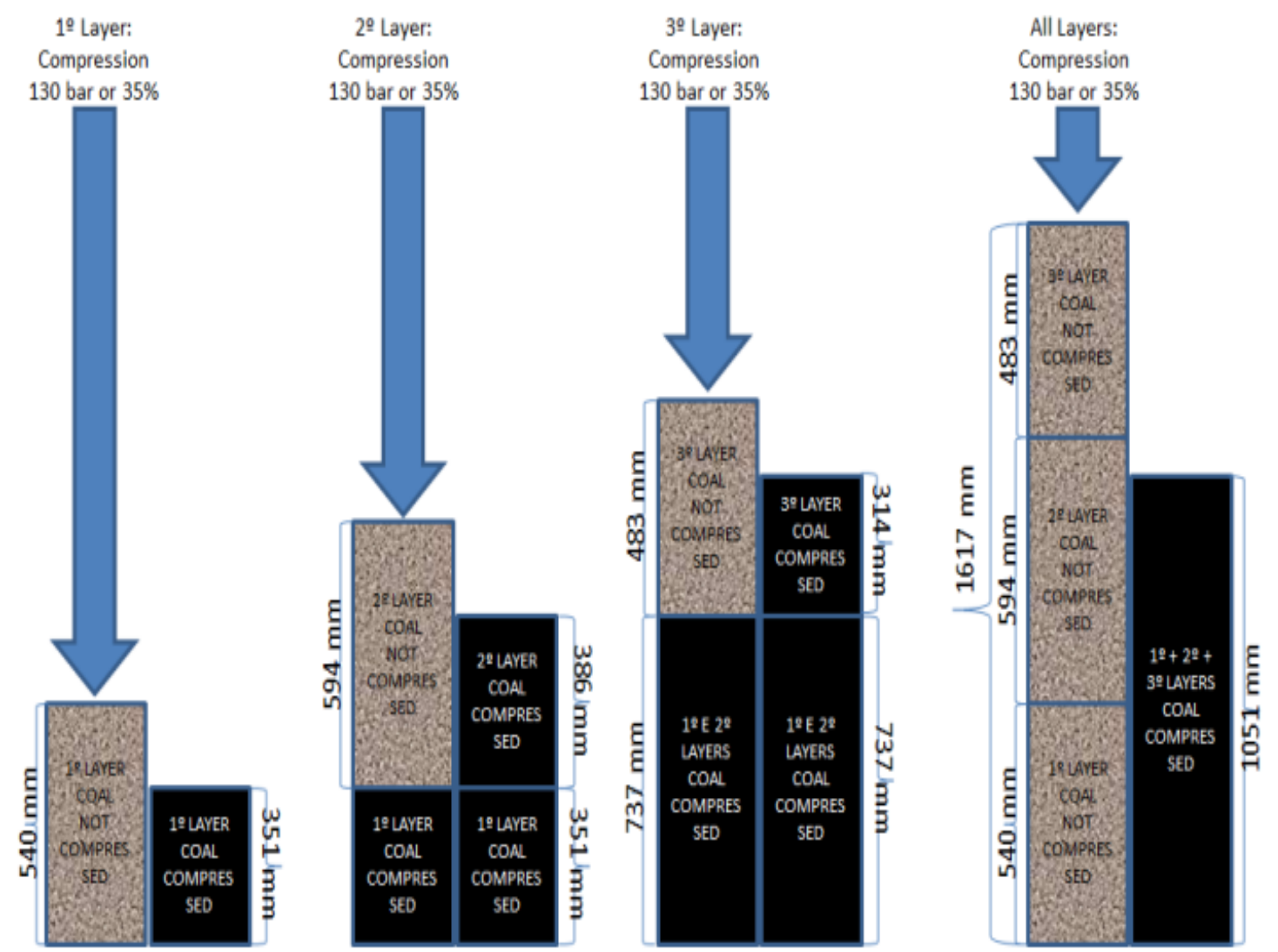

Fig. 1 Illustration of distributed and stamped coal blend.

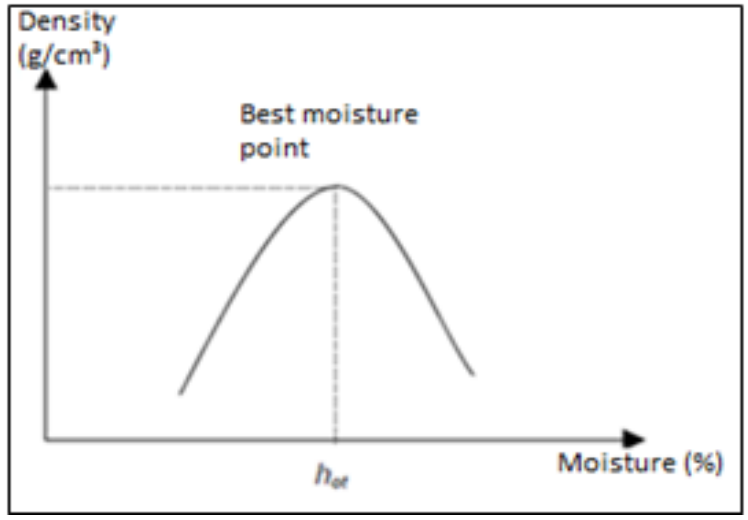

Fig. 2 Moisture versus density.

illustrates tests performed in general solids. The water humidifies the particles and facilitates the arrangement, therefore increasing the specific dry mass $\left(\mathrm{kg} / \mathrm{m}^{3}\right)$. However, after a percentage, the water amortizes the compression and it starts to have more water than solid, therefore, decreasing the dry density.

Several different stamp systems are used in batteries like heat recovery and by products or are under study.
The density obtained from these processes can reach $1.14 \mathrm{t} / \mathrm{m}^{3}$, which means an increase of about $54 \%$ in the density of the coal cake charged, compared with charge without stamp.

The design system installed at TKCSA, has a coal cake density specification between $1.05 \mathrm{t} / \mathrm{m}^{3}$ and 1.10 $\mathrm{t} / \mathrm{m}^{3}$, however tests performed at the start of operating point to higher values around $1.12 \mathrm{t} / \mathrm{m}^{3}$.

At TKCSA, the blended coal size fraction is lower than $3.35 \mathrm{~mm}$ which is controlled in the range of $81 \%-89 \%$.

Fig. 3 shows the increase of compression rate in the lab stamp at TKCSA, keeping constant the particle size of the sample, with moisture ranging from $8.3 \%$ to $9.2 \%$.

The particles are kept at constant size and the moisture at $9.2 \%$, after the stamp process, the coal cake density increases exponentially. From a certain point, an increase at stamp pressure has no longer effect to 


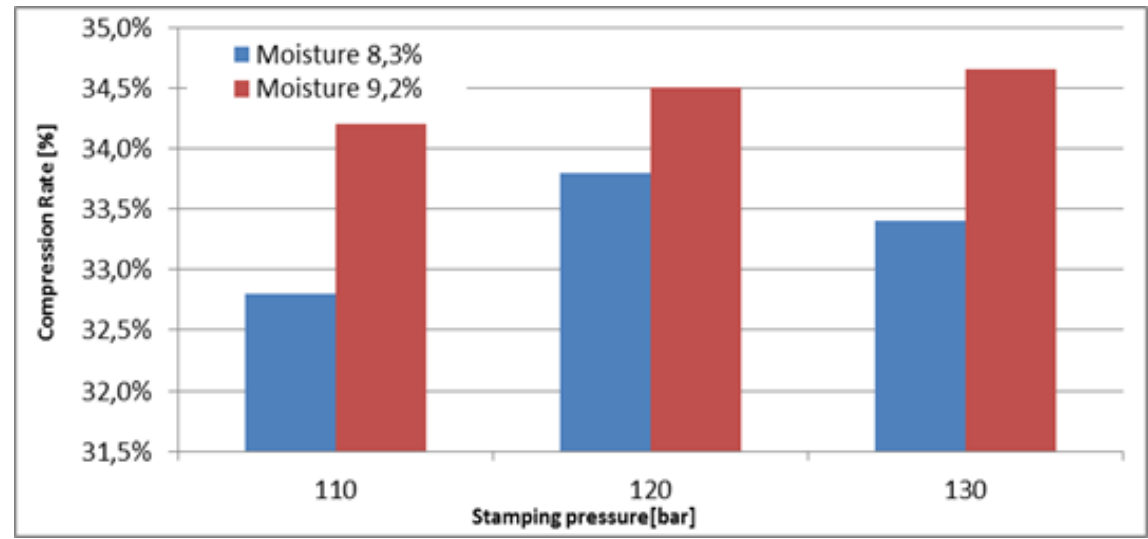

Fig. 3 Correlation of stamping pressure, moisture and compression rate of the lab stamp at TKCSA.

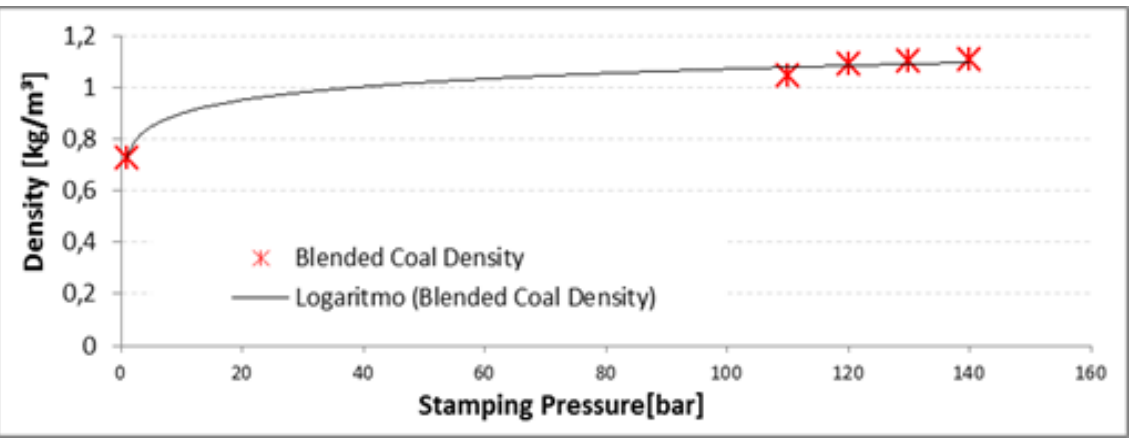

Fig. 4 Correlation of density and stamp pressure of the lab stamp at TKCSA.

increase the coal cake density. Fig. 4 shows this correlation found in the lab stamp at TKCSA.

\section{Stamping Charger System}

The stamping charger system at TKCSA uses a coal storage silo, a positioner to control the height of the distributer and two stamps for compression. This system has instruments for measuring the positions of stamps, laser for positioning the hopper and pressure instruments to check the compression.

\subsection{Methodology}

The study was initiated with pilot tests in the stamp at TKCSA laboratory using particle size and moisture within the specified parameters. Using the lab stamp, a lot of density tests were performed for different stamp pressures.

After testing in laboratory, machine tests were started seeking repeatability of the compression rate reached in laboratory for a certain stamp pressure.

\subsection{Density Calculation}

The density of the stamped blended coal is calculated using the volume of the tray and the apparent density of the blended coal.

The volume of coal inside the tray is calculated using the width and length of the tray which are 3.45 and 12.9 $\mathrm{m}$, respectively, and the height is given by the position of the distributer, which is $540 \mathrm{~mm}$ in the first layer. Fig. 5 represents the volume of the stamped coal cake.

The bulk density of the blended coal is $0.73 \mathrm{t} / \mathrm{m}^{3}$.

Using the stamp system with $35 \%$ compression rate, the height of the stamped coal cake can be calculated by Eq. (1).

Height_Stamped $=($ Height_Distributed Height_Base $) *(1$ - Compression_rate) (1) Height_Stamped $=(540-0) *(1-0.35)$

Height_Stamped $=351 \mathrm{~mm}$

The calculation of the final density of the stamped coal cake is done considering the Law of Lavoisier (1743) which says "In a chemical reaction mass is 


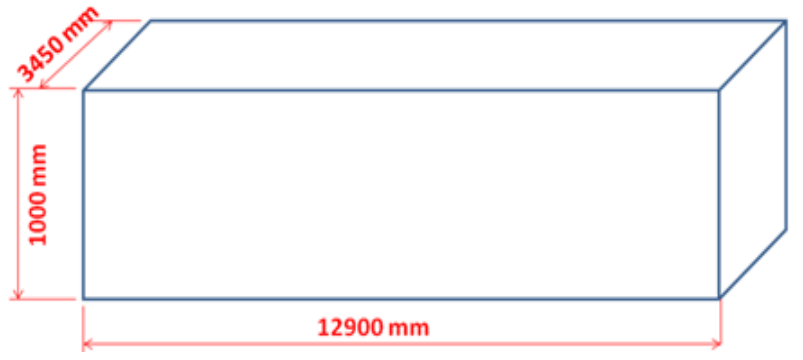

Fig. 5 Dimensions of stamped coal cake.

conserved because no creation or destruction of atoms occurs. Atoms are conserved, they just rearrange themselves." Using this law, we know the initial weight will be equal to the final weight, Eq. (2) and thus the density of the stamped coal cake can be calculated by Eq. (3).

$$
\begin{array}{r}
\text { Mass_Initial = Mass_Final (2) } \\
\text { Mass }=\text { Density*Volume (3) } \\
\text { Density_initial*Volume_initial }= \\
\text { Density_Final*Volume_final } \\
\text { Density_initial*3.45*12.9*0.540 = } \\
\text { Density_final } * 3.45 * 12.9 * 0.351 \\
0.73 * 24.0327=\text { Density_final } * 15.621255 \\
\text { Density_final }=(0.73 * 24.0327) / 15.621255 \\
\text { Density_final }=1.123 \mathrm{t} / \mathrm{m}^{3}
\end{array}
$$

The calculations of the other three layers can be done using the same formula.

Fig. 1 illustratively shows the distributed and stamped coal considering a compression rate of $35 \%$.

\section{Production Calculation}

Coke production depends on two factors: number of pushed coke oven and average coke weight per oven.

The total coke production is the sum of the coke weight produced in each oven, Eq. (4).

$$
\sum_{\mathrm{n}=1}^{\text {Total Oven Pushed WeightCokeOven n (4) }}
$$

To simplify the calculation of the production, the average coke weight per oven multiplied by the number of pushed ovens is used, Eq. (5).

Production $=\mathrm{N}^{\circ}$ OvensPushed $*$ WeightCokeAverage

To increase the production, the number of pushed oven or the coke weight per oven must be increased.
When the maximum pushed oven per day are reached, the only possibility to increase production is to increase the coke weight per oven or the density of the coal cake.

Due to the lack of a scale system to measure the weight coal cake charged, the theoretical average weight is calculated using, the volume of the tray, one meter of stamped height, the density of the stamped coal at 1.123 and moisture at 9.2\%, Eq. (6).

CoalWeight_Oven $=$ Volume_Tray*Density_final $*(1-$ Moisture) (6)

CoalWeight_Oven $=3.45 * 12.9 * 1 * 1.123 *(1-0.092)$

CoalWeight_Oven $=45.38 \mathrm{t}$

Assuming a yield of 0.73 for a coke/coal, it is possible to calculate the average coke weight produced by oven, Eq. (7).

$$
\begin{array}{r}
\text { CokeWeight_Oven }=\text { CoalWeight_Oven*Yield }(7) \\
\text { CokeWeight_Oven }=45.38 * 0.73 \\
\text { CokeWeight_Oven }=33.12
\end{array}
$$

\section{Results and Discussions}

There is an increase in the amount of coal consumed and an increase in the coke produced when the stamping charger is used in automatic mode. This increase of coke production happens because of the maximization of the coal cake density, which the automatic stamping charger provides.

Fig. 6 represents the coke weight per oven $(29.73 \mathrm{t}$ is defined as $100 \%$ ) and the percentage of charged ovens stamped in automatic mode over the past six months. From January until mid-March, the automatic stamping charger had been in test and was being optimized, since then it has been verified an increase in the coke weight per oven.

The annual coke production is based on the number of pushed ovens. The total output is directly affected by the coal cake density. Fig. 7 represents the monthly average coke weight per oven with the reference of $29.73 \mathrm{t}$ as $100 \%$, the annual coke production for 50.442 pushed ovens and the percentage of ovens stamped in automatic mode. 


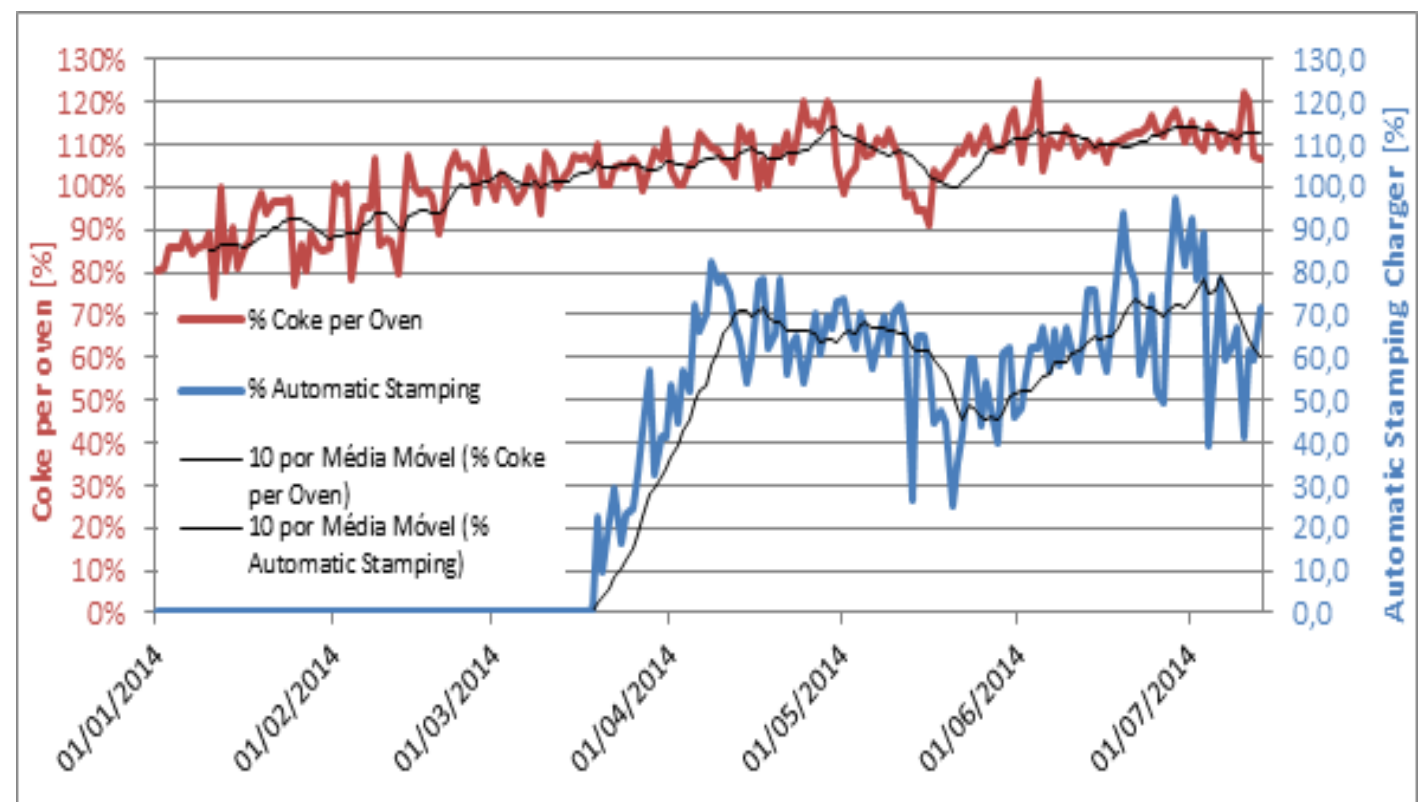

Fig. 6 Percentage coke weight per oven and percentage of ovens stamped in automatic mode.

\begin{tabular}{|c|c|c|c|}
\hline Month & $\begin{array}{c}\text { Average coke } \\
\text { per oven (\%) }\end{array}$ & $\begin{array}{c}\text { Annual prodvction for } \\
50.442 \text { pushed overs ( } t \text { ) }\end{array}$ & $\begin{array}{c}\text { Percentage Avtomatic } \\
\text { Stamping Charger } \\
\text { vsed (\%) }\end{array}$ \\
\hline Jan/14 & 88 & 1.313 .510 & 0,00 \\
Feb/14 & 97 & 1.455 .756 & 0,00 \\
Mar/14 & 104 & 1.553 .614 & 12,80 \\
\hline Apr/14 & 110 & 1.634 .321 & 65,90 \\
Mai/14 & 106 & 1.596 .489 & 55,60 \\
Jun/14 & 112 & 1.675 .683 & 68,10 \\
\hline
\end{tabular}

Fig. 7 Coke production and automatic stamping charger.

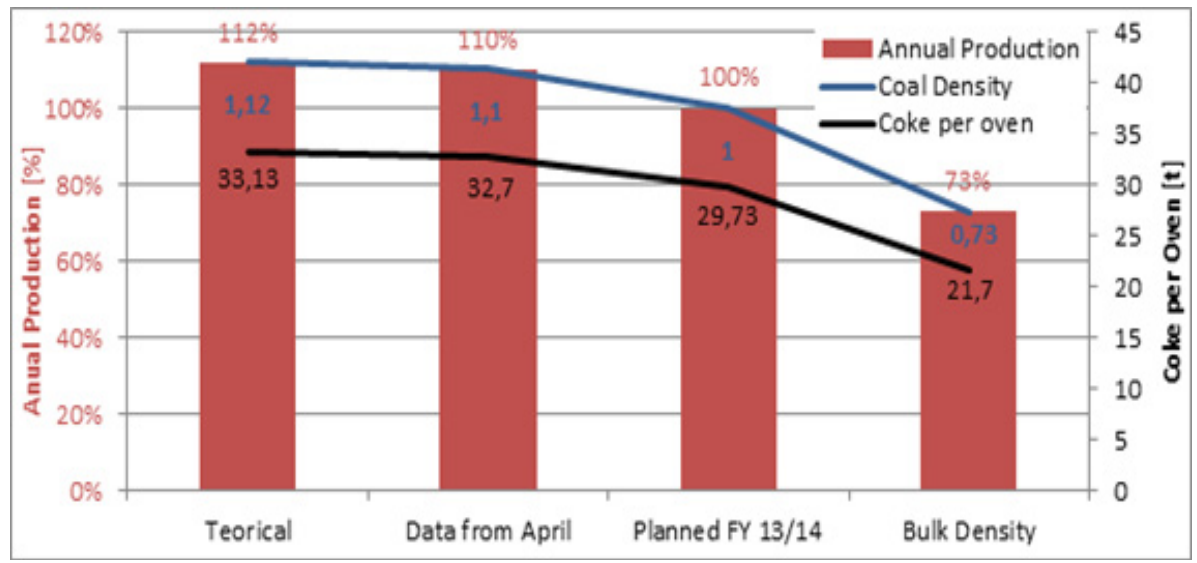

Fig. 8 Theoretical basis for annual production, coke per oven, and coal density for 1 meter height stamped.

Fig. 8 shows the variation of annual production, the coke weight per oven and the coal cake density for one meter height, with a the number of pushed ovens at 50.442 per year and a coke/coal yield of $73 \%$ at TKCSA.

\subsection{Environment}

Particulate emission in the atmosphere happens 
during the process of charging the coal cake due to pressure and temperature inside the oven. The environment impact is reduced using an exhaust system which prevents particles reaching the atmosphere.

The automatic stamping charger contributes with the exhaust system, and it ensures the entire coal cake is stamped leaving no coal "loose" in the cake, i.e., compression in automatic guarantee consistency to the coal cake, helping it minimize particulate emissions.

\subsection{Quality}

The use of automatic stamping charger improves the coke quality parameters and allows the use of lower quality coal (Alternative C) to form the blend, consequently, decreasing the production cost.

This technology has allowed the use of Alternative C at levels above $25 \%$ while remaining the CSR at quality specification. Fig. 9 shows the maintenance of CSR versus the percentage of Alternative $\mathrm{C}$ in coal blend.

\subsection{Control, Reporting and Reliability}

The stamping charger process is controlled by a PLC. The control system has functions to monitor and identify each compression to provide information about the process. This information generated is presented in Fig. 10.

The compression rate presented in the report is of great value to measure the efficiency of the compression system and to calculate the weight of the coal cake charged.

Positioner and instruments that are used to control the system have an error of $10 \mathrm{~mm}$. The measure of the position has an error of only $1 \mathrm{~mm}$.

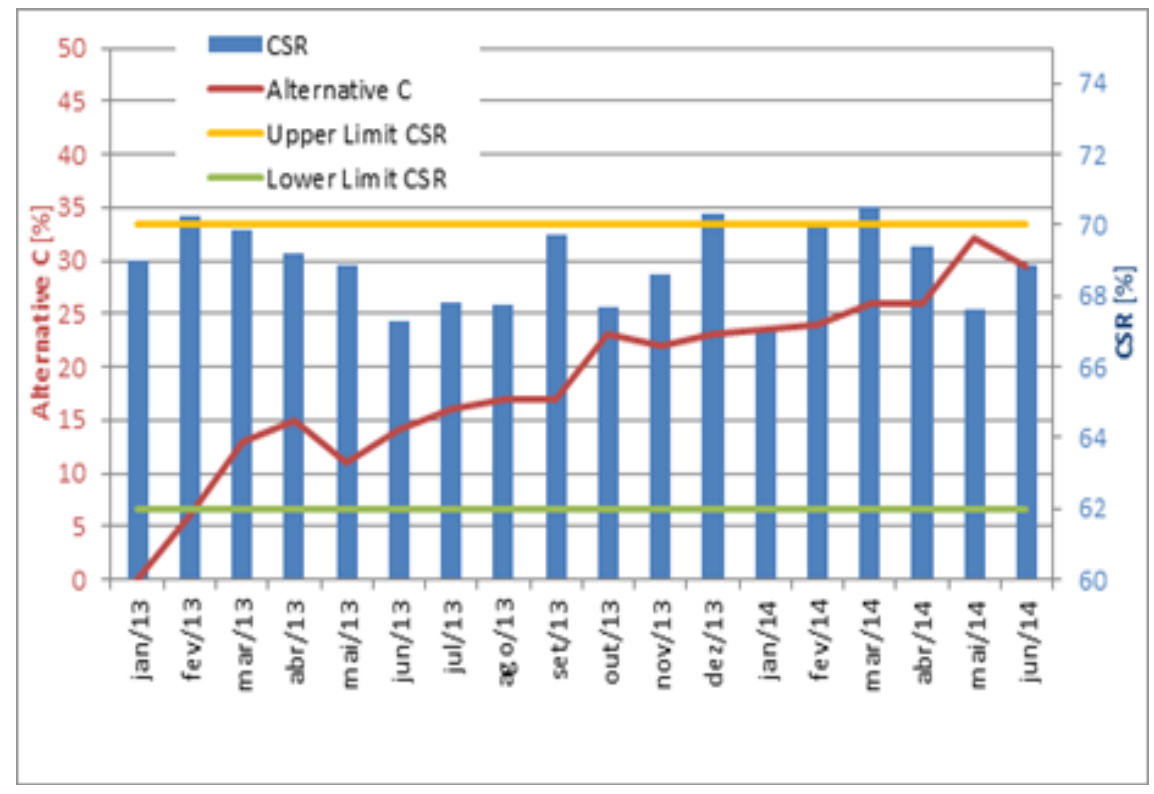

Fig. 9 CSR maintenance versus participation of Alternative $C$ in coal blend.

\begin{tabular}{|c|c|c|c|c|c|}
\hline \multicolumn{7}{|c|}{ RELATORIO 31C } & \multicolumn{1}{c|}{$12 / 13 / 20135: 28: 54$ AM } \\
\hline \multicolumn{5}{|c|}{ DETALHES } \\
\hline Cam. & $\begin{array}{c}\text { Altura } \\
\text { Espalham. }\end{array}$ & $\begin{array}{c}\text { Altura } \\
\text { Acabam. } \\
\text { Meta }\end{array}$ & $\begin{array}{c}\text { Altura } \\
\text { Acabam. } \\
\text { Real/Média }\end{array}$ & $\begin{array}{c}\text { Taxa } \\
\text { Compress. } \\
\text { Meta }\end{array}$ & $\begin{array}{c}\text { Taxa } \\
\text { Compress. } \\
\text { Real }\end{array}$ \\
\hline $1^{a}$ & 540 & 351 & 371 & 35 & $31.30 \%$ \\
\hline $2^{a}$ & 945 & 737 & 707 & 22 & $25.19 \%$ \\
\hline $3^{a}$ & 1220 & 1049 & 1026 & 14 & $15.90 \%$ \\
\hline
\end{tabular}

Fig. 10 Automatic stamping charger report. 


\section{Automatic Stamping Charger-Stamping of Blended Coal-Theorical Study and Practice Analysis at TKCSA}

Reports are generated for each oven charged, thus facilitating monitoring of the compression rate, which constitutes an important indicator of the performance of the automatic stamping charger.

\section{Conclusions}

The moisture of the blended coal at $9.2 \%$ and the compression pressure at 130 bar provided the best compression rate (related to TKCSA blended coal), around $35 \%$ and density of $1.12 \mathrm{t} / \mathrm{m}^{3}$. In industrial scale a density of $1.10 \mathrm{t} / \mathrm{m}^{3}$ was obtained, indicating a compression rate very close to the rate obtained in the laboratory.

The stamping charge in automatic mode provides a better control of the coal cake height to be charged, with lower deviations then when operations are done in manual mode, increase coal cake density and consequent coke production increase.

The coke quality remained stable even with increased share of Alternative $\mathrm{C}$ coal that has lower quality and lower cost, and this effect is partly attributable to the stamping charger process.

The coal cake height can be individualized, aiming at a target for net coking time, which can be used to maximize productivity and/or mitigate losses when a shutdown happens.

\section{Acknowledgments}

We thank Paul Buaiz consultant for guidance and support throughout the execution of the work, the staff of the coke plant, the Technical Unit for the immense support and knowledge shared, to the staff from Laboratory, Operation and Maintenance, and all the people who somehow contributed to the development of this study.

\section{References}

[1] Coelho, R. J. 2003. "Modelos de Previsão de Qualidade Metalúrgica do Coque a Partir da Qualidade dos Carvões Individuais e do Coque Obtido no Forno Piloto de Coqueificação da CST.” M. Sc. thesis, Universidade Federal de Ouro Preto. Rede Temática em Engenharia de Materiais.

[2] Abel, F., Rosenkranz, J., and Kuyumcu, H. Z. 2009. "Stamped Coal Cakes in Cokemaking Technology. Part 1-A Parameter Study on Stampability." Ironmaking and Steelmaking 36 (5): 321-6.

[3] Abel, F., Rosenkranz, J., and Kuyumcu, H. Z. 2009. "Stamped Coal Cakes in Cokemaking Technology. Part 2-The Investigation of Cake Strength." Ironmaking and Steelmaking 36 (5): 327-32.

[4] Kuyumcu, H. Z. 1990. "Cokemaking by Stamp Charging." Presented at the 6th International Iron and Steel Congress, Nagoya, Japan. 